\title{
RECURSOS HÍDRICOS EM SALA DE AULA: CONSTRUÇÃO DE MAQUETE COMO METODOLOGIA ATIVA ${ }^{1}$
}

\author{
WATER RESOURCES IN THE CLASSROOM: \\ CONSTRUCTION OF A SCALE MODEL AS AN ACTIVE METHODOLOGY
}

\author{
Janete Facco Facco 2 , Janete Webler Cancelier ${ }^{3}$ e Liziany Muller Medeiros ${ }^{4}$
}

\section{RESUMO}

Os recursos hídricos são necessários para a sobrevivência humana, para a fauna, flora e, para o desenvolvimento das atividades econômicas. No processo de construção da conscientização ambiental, escola e universidade possuem significativo papel, tendo em vista que podem desenvolver atividades que auxiliem na formação de sujeitos críticos perante a realidade colocada. Uma metodologia ativa que pode ser empregada para compreensão do uso do solo em microbacias e seus impactos, é a confecção de maquetes, que propicia o conhecimento da realidade local a partir da espacialização dos eventos. Dessa forma, o objetivo deste artigo é apresentar oficinas pedagógicas desenvolvidas a partir de um Projeto de Extensão Universitária, com estudantes da educação básica e do ensino superior para a construção de maquetes de uma microbacia. A estratégia adotada foi o emprego do método indutivo, com abordagem qualitativa. Como resultado, observa-se que a construção das maquetes estimulou o interesse educativo, possibilitando a consolidação, de forma prática, de conceitos e temáticas, a partir de uma visão sistêmica e interdisciplinar.

Palavras-chave: Práticas pedagógicas, Bacia hidrográfica, Ensino-aprendizagem. Geografia. Metodologia ativa.

\section{ABSTRACT}

Water resources are required for human survival, for fauna and flora, and for the development of economic activities. In the process of building environmental awareness, both school and university play a significant role, considering that they can develop activities that help with the formation of critical subjects. An active methodology that can be applied to comprehend the land use in micro-watersheds and their impacts is the making of scale models, which provides knowledge of the local reality from the events spatialization. Therefor, this article aims to present pedagogical workshops elaborated in a University Extension Project, with elementary school and university students to build scale models of a micro-watershed. The strategy adopted was the inductive method with a qualitative approach. As a result, the construction of scale models stimulated educational interest, enabling the learning of concepts and themes in a practical way, based on a systemic and interdisciplinary view.

Keywords: Pedagogical practices, Watershed, Teaching-learning, Geography, Active methodology.

1 Artigo teórico-prático apresentando uma atividade de Extensão realizada no Curso de Licenciatura em Educação do Campo, modalidade educação a distância, da Universidade Federal de Santa Maria - UFSM.

2 Professora da educação básica do estado de Santa Catarina.E-mail janetefacco1@gmail.com

3 Professora Formadora UAB/CAPES da Universidade Federal de Santa Maria (UFSM). E-mail: janetewc@gmail.com 4 Professora do Programa de Pós-Graduação em Extensão Rural da Universidade Federal de Santa Maria, Santa Maria e Coordenadora do Curso de Licenciatura em Educação do Campo da UFSM. E-mail: lizianym@cead.ufsm.br 


\section{INTRODUÇÃO}

Os métodos de ensino convencionais, disseminados em vários espaços educativos, que colocam o professor como protagonista do processo de ensino aprendizagem atualmente, não surtem mais os efeitos esperados para despertar o interesse nos estudantes, gerando baixo rendimento, participação e interação nas aulas (COSME et al., 2019). Bastos (2006) ressalta que metodologia ativa é um processo de ensino em que a aprendizagem depende do próprio estudante, e o professor atua como facilitador ou orientador para que o estudante faça pesquisas, reflita e decida, por ele mesmo, o que fazer para atingir um objetivo.

Conforme Berbel (2011), as metodologias ativas têm o potencial de despertar a curiosidade à medida que os estudantes se inserem na teorização e trazem elementos novos, ainda não considerados nas aulas ou na própria perspectiva do professor, assim os estudantes são valorizados e são estimulados os sentimentos de engajamento, percepção de competência e de pertencimento, além da persistência nos estudos, entre outras. Metodologias ativas são processos interativos de conhecimento, análise, estudos, pesquisas e decisões individuais ou coletivas, que estimula a (autoaprendizagem), desperta a curiosidade e, ao mesmo tempo, oferece meios para que o estudante possa desenvolver capacidade de análise de situações (BASTOS, 2006).

A promoção de um ensino de Geografia mais ativo, significativo e com cada vez mais relação com a realidade dos estudantes aparece como um caminho satisfatório para um ensino e uma aprendizagem mais eficaz, mostrando aos estudantes, novamente, o papel e a importância da Geografia para a compreensão da realidade (CARNEIRO, 2019). Cosme et al. (2019), revelam que, o professor de Geografia, ao utilizar metodologias ativas, tem a possibilidade de romper com a atitude passiva de apenas escutar o estudante, na qual há absorção do conhecimento sem refletir sobre o mesmo, como uma prática que não inspira sua participação na construção do conhecimento.

Cabe ao professor de Geografia, com o apoio da escola, despertar e promover a autonomia e o protagonismo de seus estudantes, inserindo em suas aulas algumas metodologias ativas, bem como proporcionar aulas que estimulem a criatividade e a ludicidade dos estudantes (CARNEIRO, 2019). A construção de maquetes se insere como uma metodologia ativa de ensino, na qual o estudante participa efetivamente de todas as etapas que compõem a sua estruturação, discutindo, opinando e produzindo de maneira que o conhecimento é estruturado mediante as ações desenvolvidas ao longo de todo o processo (COSME et al., 2019).

A maquete, enquanto recurso didático, permite desenvolver habilidades cognitivas no que tange a relação teoria-prática, na compreensão da linguagem cartográfica e das relações espaciais entre os elementos do espaço geográfico. Utilizar maquetes no processo de ensino aprendizagem de Geografia, possibilita construir o conhecimento de maneira acumulativa, e é possível observar, na participação dos estudantes envolvidos, o desenvolvimento de competências, algo presente nas práticas pedagógicas das metodologias ativas (COSME et al., 2019). 
Neste contexto, a partir da maquete o estudante, de acordo com o seu nível cognitivo, passa a desenvolver e dominar conceitos espaciais e suas representações em diversas escalas, de uma forma prática da teoria construtivista do conhecimento e uma prática escolar em busca da alfabetização cartográfica e geográfica e entendimento da realidade (OLIVEIRA; MALANSKI, 2008). Ainda permite a percepção do abstrato no concreto (LUZ; BRISK, 2009; COSME et al. 2019), estimulando o estudante a fazer uma análise 3D, integrada e generalizadora dos fenômenos espaciais (OLIVEIRA; MALANSKI, 2008). Conforme Simielli et al. (1992), a maquete pode aparecer como o processo de restituição do 'concreto' (relevo) a partir de uma 'abstração' (curvas de nível), centrando aí sua real utilidade, complementada com os diversos usos deste modelo concreto trabalhado pelos estudantes.

Portanto, a partir da maquete o professor pode explorar diferentes conteúdos da Geografia Escolar, tanto de aspecto físico (geomorfologia, hidrografia, geologia entre outros) quanto humano (urbanização, cultura, economia etc.), ou inter-relacionar ambos em diferentes escalas cartográficas e geográficas sobre o modelo (OLIVEIRA; MALANSKI, 2008).

Castellar (2011, p. 122), em seus apontamentos já evidenciava que “[...] a linguagem cartográfica torna-se um meio à medida em que permite relacionar conteúdos e fatos; permite a compreensão, pelos alunos, de parte e da totalidade do território". Portanto, a elaboração de maquetes nas aulas de Geografia possibilita o sentido de lugar visto como o locus do sujeito que o constrói, ao mesmo tempo em que constitui a si mesmo se relacionando com o mundo e com a coletividade social, aos poucos vai tomando importância para o estudante através do aprofundamento necessário para desenvolver o projeto (COSME et al., 2019).

Neste contexto, a oferta de oficinas de construção de maquetes como metodologia ativa para resolução de problemas em microbacias surge como uma prática educativa potencializadora para re(significar) processos educacionais que garantam, aos estudantes da disciplina de Geografia, autonomia e a construção colaborativa de saberes, atendendo um ensino com qualidade e a educação libertadora e problematizadora proposta por Paulo Freire.

Neste contexto, o presente relato tem o objetivo de apresentar o resultado de ações de um Projeto de Extensão (realizado) no formato de oficinas na disciplina de Geografia para estudantes do sexto ano do ensino fundamental de uma escola de educação básica localizada no município de Santa Maria-RS e para estudantes do sétimo semestre de um curso superior de licenciatura com habilitação em Ciências Humanas da Universidade Federal de Santa Maria, bem como analisar as contribuições dessa atividade para a formação dos estudantes.

\section{MATERIAL E MÉTODOS}

O trabalho desenvolvido para oferta das oficinas seguiu os princípios da investigação-ação educacional e diálogo problematizador freiriano, assumindo caráter democrático com a intencionalidade voltada 
à promoção de mudanças sociais, no qual o diálogo se constitui na essência maior da educação libertadora. A investigação-ação foi centrada nos problemas reais enfrentados pelos sujeitos, buscando compreender e sendo compreendida como uma forma dos mesmos pensarem sobre suas aflições, adotando uma postura investigativa e tendo como meta o desenvolvimento profissional em uma rede de trabalho que considera como ponto de partida a experiência e saberes dos participantes, gerando uma cultura colaborativa.

A metodologia consistiu na oferta de uma oficina para dois níveis de ensino (ensino fundamental e ensino superior), com quatro horas de duração cada, sendo que $1 \mathrm{~h}$ teórica e $3 \mathrm{~h}$ prática.

A investigação-ação envolveu um processo histórico e social de transformação da prática educativa concreta em que os próprios atores envolvidos sentiram a necessidade de inovações. Seu método central é uma espiral (autorreflexiva), formada por ciclos sucessivos de planejamento, ação, observação e reflexão, conduzidos e negociados pelos agentes implicados, com o propósito de intervir em sua prática educativa e melhorá-la.

Esta espiral vincula a reconstrução do passado com a construção de um futuro concreto e imediato por meio da ação (CARR; KEMMIS, 1988). A perspectiva deste tipo de investigação é transformar a prática educativa em vez de apenas gerar conhecimentos.

A produção e utilização dos conhecimentos direcionam-se a partir da prática (ELLIOTT, 1993). Com as oficinas buscou-se mobilizar os sujeitos para uma prática diferenciada da tradicional, a investigação-ação permitiu um mapeamento da realidade existente no contexto escolar, principalmente em relação ao estudo do uso do solo em microbacias e seus impactos, e como a confecção de maquetes pode propiciar o conhecimento da realidade local a partir da espacialização dos eventos, problematizando-a e levantando temáticas de aprendizagem urgentes para intervenção e criação de soluções inovadoras.

A prática investigativa concretizou-se como um processo formativo, conduzindo à aprendizagem de como fazê-la, favorecendo o desenvolvimento dos sujeitos envolvidos no processo. Cada fase cíclica representou uma nova proposta para ser investigada e é o meio pelo qual foi se (re)configurando o trabalho cotidiano, ativando-se recursos mediadores auxiliares e sociais.

As etapas de desenvolvimento seguiram a propostas da espiral reflexiva:

\section{a) Planejamento}

Visou a elaboração e o planejamento da oficina, etapas antecessoras a ação propriamente dita, onde foi necessário refletir sobre como utilizar as maquetes perpassando conhecimentos sobre o uso do solo e suas consequências em microbacias aliando os conceitos de microbacias, escala, altitude, curvas de nível, rio principal, nascentes, bem como as projeções de uso futuro e de planejamento de utilização nas mais diversas áreas, construindo uma base para as ações futuras.

Nesse momento a equipe foi formada, contando com três (3) professoras de instituições de ensino superior que possuem experiência na elaboração de maquetes e dois (2) tutores que auxiliaram no desenvolvimento das atividades práticas. 
Após a formação da equipe, foram realizados encontros para planejar as oficinas, as estratégias e metodologia a serem adotadas. Também foi realizado um contato prévio com a direção/coordenação e as professoras responsáveis pela disciplina de Geografia das turmas que seriam aplicadas as oficinas, com o objetivo de verificar se elas possuíam interesse na realização da oficina.

A ideia da realização das oficinas partiu das pesquisadoras, que buscavam inserir a universidade na escola a partir das ações de extensão. As ações de extensão propostas, buscaram promover a qualificação da escola e de educandos de cursos de licenciatura do ensino superior, na perspectiva da troca de saberes e experiências entre os sujeitos envolvidos. Entende-se que a base das práticas educacionais deve partir do espaço em que vive o aluno, objetivando a inserção deste no processo educativo, de modo vivo e dinâmico (FREIRE, 1999).

Ao final das ações, foram aplicados 37 questionários de avaliação das oficinas, dois com representantes da escola de Ensino Fundamental (direção e professora de Geografia) e 35 para os estudantes do nível superior.

\section{b) Ação}

Foi guiada pelo planejamento realizado anteriormente sem, no entanto, incorrer no erro comum de utilizar o planejamento como um guia estático e imutável.

As oficinas foram realizadas durante o primeiro semestre letivo de 2019, com uma carga horária total de 4 horas cada. Inicialmente para vinte e cinco (25) estudantes do sexto ano do ensino fundamental na escola Intendente Manoel Ribas, a qual pertence a rede municipal de educação do município de Santa Maria-RS e, sequencialmente, para trinta e cinco (35) estudantes do terceiro semestre de um curso superior com habilitação em Ciências Humanas da Universidade Federal de Santa Maria.

As oficinas foram constituídas de uma parte teórica (1 hora), onde foram abordados conteúdos sobre os cursos de um rio, conceitos de nascente, foz, delta, o que é uma bacia hidrográfica, a importância dos recursos hídricos e a necessidade de sua conservação. Com isso, buscou-se identificar os conhecimentos prévios dos estudantes sobre a temática, mais especificamente, sobre escala, altitude, curvas de nível. Na sequência, foi apresentado o propósito da construção da maquete, bem como os materiais necessários. Na parte prática (3 horas) foram realizados o planejamento e a construção em sala de aula das maquetes.

Os materiais necessários para a realização das atividades práticas foram fornecidos pelo Projeto de extensão "Práticas pedagógicas inovadoras através do uso das TIC para potencializar o processo de ensino aprendizagem de educandos do curso de Licenciatura em Educação do Campo da Universidade Federal de Santa Maria”. Os materiais utilizados foram: folhas de EVA; canetinha hidrocor azul claro e preta; cola para isopor ou EVA, clips com espessura fina; tesoura; papelão de $30 \mathrm{X} 30 \mathrm{~cm}$ mais grosso para ser a base da maquete; canetas coloridas. Cabe destacar que é possível utilizar outros materiais, considerando a realidade de cada espaço escolar. 
As maquetes foram construídas individualmente, cada estudante recebeu um desenho, em folha A4, de curvas de nível de 100 em 100 metros de uma microbacia local (Figura 1), referente ao espaço em que os estudantes estão inseridos, visando facilitar a localização de elementos naturais e construídos presentes.

Figura 1 - Curvas de nível da microbacia

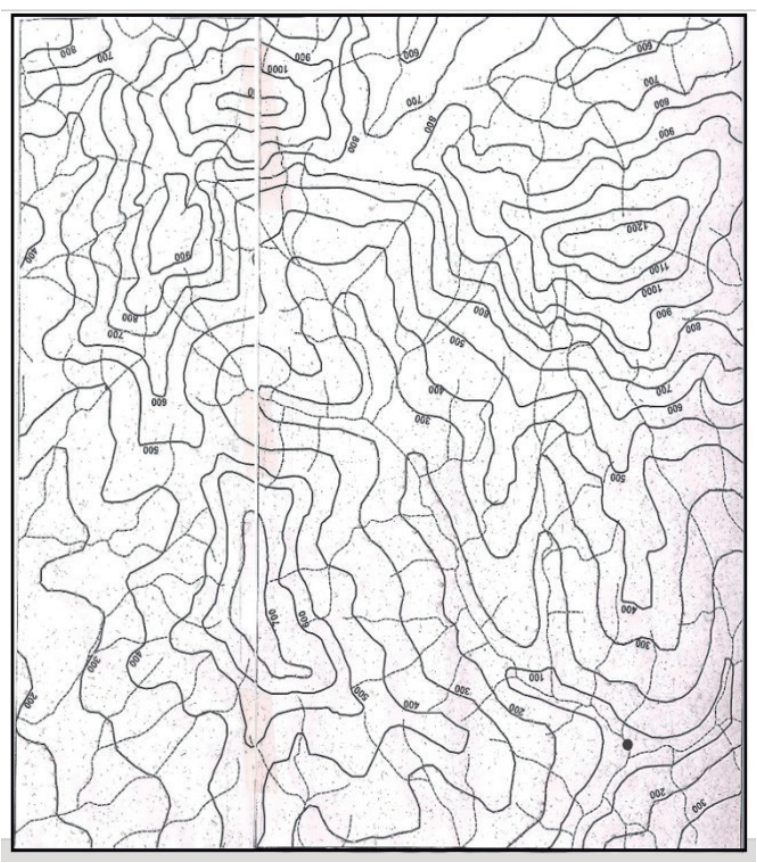

Fonte: Arquivo pessoal autores (2020)

Durante a oficina, foi explicado aos estudantes a importância da escala no trabalho de construção da maquete, permitindo que os mesmos elaborassem correlações e estabelecessem entendimento de quantas vezes o real foi reduzido para que coubesse na folha A4. No caso utilizado, cada curva de 100 metros foi reduzida cem vezes seu tamanho real.

Para que a maquete pudesse ter uma base firme e manuseada pelos estudantes, foi sugerido a utilização de um pedaço de papelão de $30 \times 30 \mathrm{~cm}$. Com a folha das curvas de nível em mãos, os estudantes iniciaram o trabalho localizando e destacando, com uma cor qualquer de canetinha, a linha de 100 metros, que é a primeira camada. Na etapa da delimitação das curvas foi realizado um acompanhamento individual com cada estudante, auxiliando para que observassem e demarcassem todas as curvas de nível seguintes. Posteriormente, com as curvas do terreno já delimitadas, a cópia do desenho (Figura 1) foi inserida sobre um pedaço de EVA, previamente recortado no formato de uma folha A4. Sequencialmente, utilizou-se um clips de espessura fina e aberto para furar a linha com a curva de 100 metros. Esses furos marcaram o EVA, onde este foi recortado, para ser colado na base de papelão, descartando o restante, "respeitando o ordenamento da placa maior para a menor de acordo com as curvas de nível desenhadas" (PEREIRA et al., 2015, p. 4). É importante destacar as curvas de 100 metros com uma tonalidade diferente, isso facilita o andamento do trabalho, demonstrado na Figura 2. 
Figura 2 - Marcação das curvas já recortadas

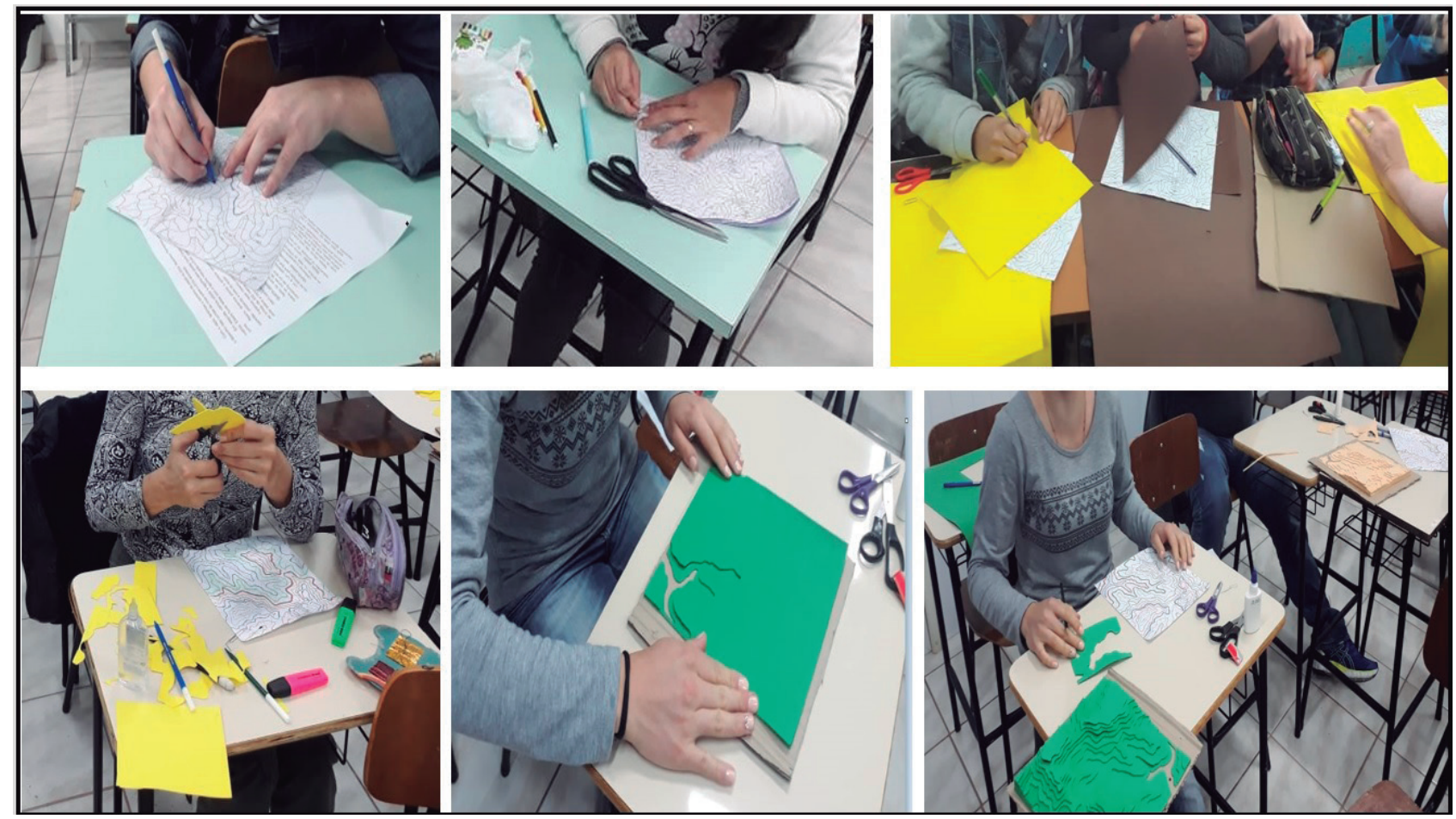

Fonte: Acervo autores (2020)

Esse mesmo processo, se repetiu para as curvas de 200, 300, 400, 500, 600, 700, 800, 900, 1000 e 1100 metros, como pode ser observado na Figura 3.

Figura 3 - Processo de construção da maquete através das curvas de níveis

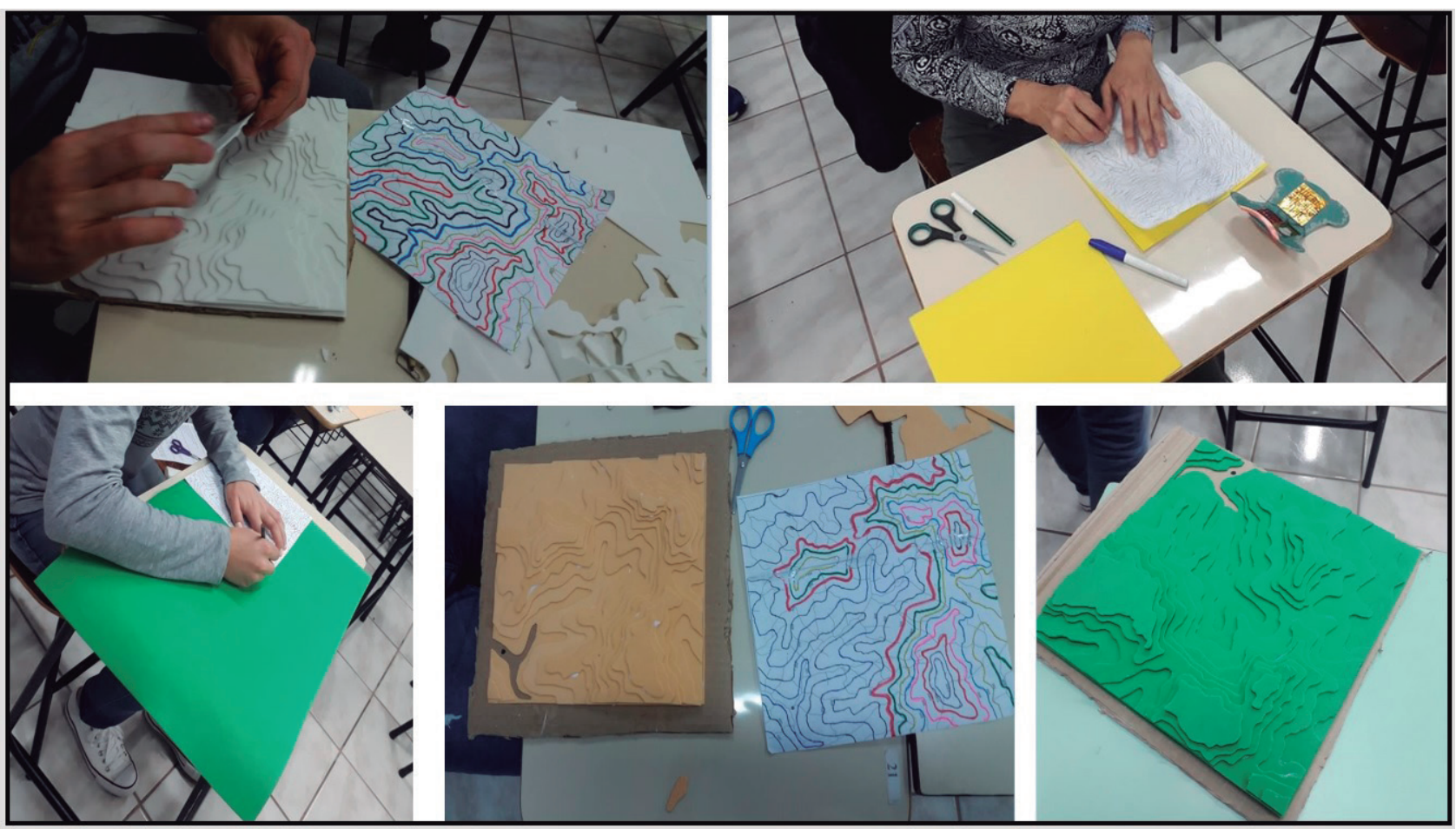

Fonte: Acervo autores (2020) 
Após ter concluído a colagem das curvas de nível, foi iniciada a etapa da inserção dos cursos d'água e seus divisores, com tonalidade azul, sobre as curvas de nível, respeitando o traçado dos rios que estão na planta. Um a um, observando cada detalhe, foram inseridos os rios. Essa etapa exigiu muita atenção para que os divisores de água fossem respeitados (Figura 4). Para facilitar a compreensão dos estudantes, relembramos que para realizar o traçado do rio principal de qualquer microbacia ou bacia hidrográfica, é necessário observar a nascente mais distante do exutório (foz) e, na sequência, demarcar os elementos existentes na microbacia, como: nascentes, rio principal, foz e ponto mais baixo do terreno

Figura 4 - Cursos d’água sobre as curvas de nível

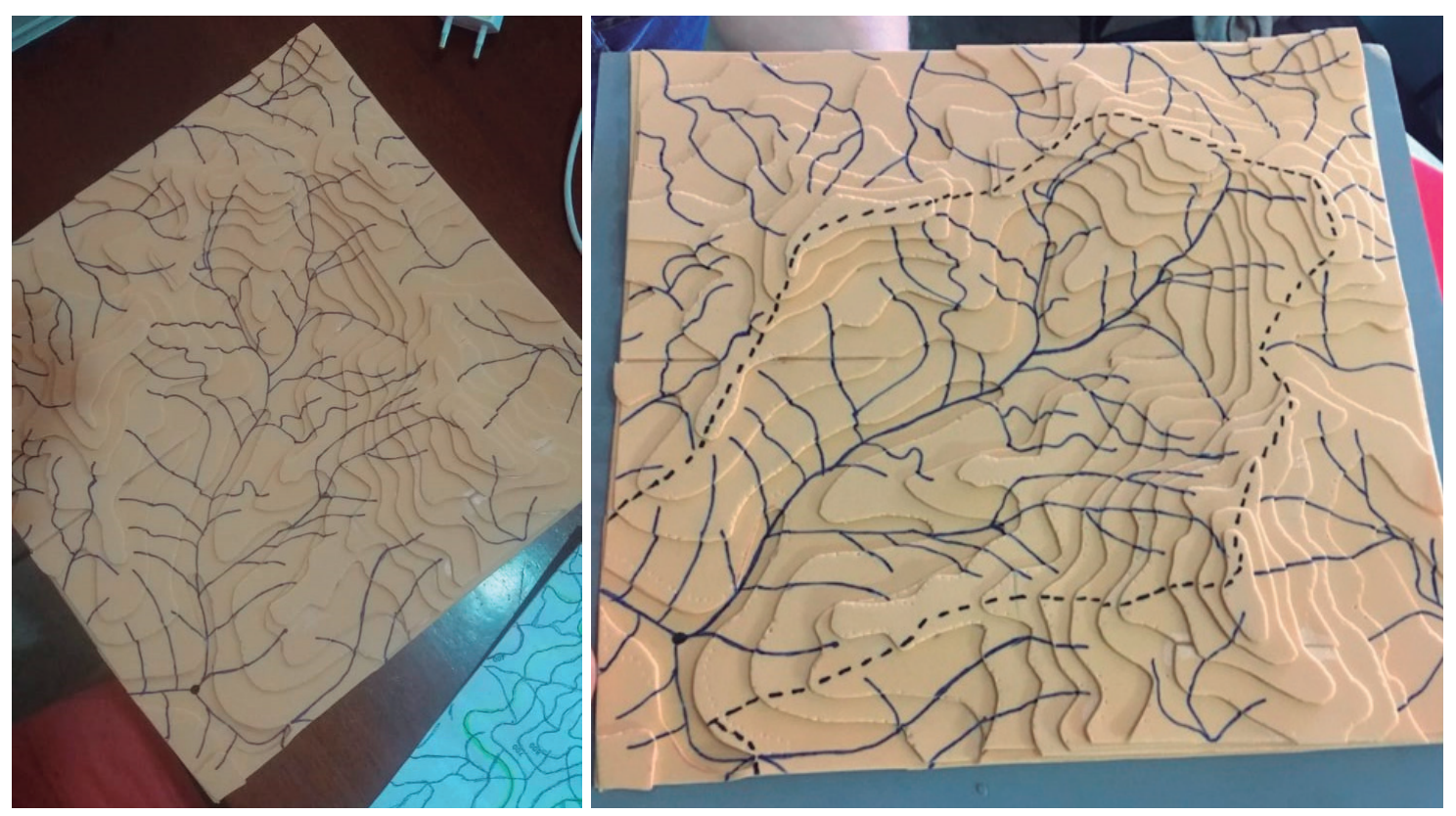

Fonte: Acervo autores (2020)

\section{c) Observação}

A Observação foi realizada pela equipe, foram avaliados dados referentes aos efeitos da ação (ofertas das oficinas), gerando uma base para a reflexão. Os dados também foram analisados a partir dos questionários respondidos pelos participantes, contribuindo para a melhoria contínua da prática, através da análise da situação contextualizada, o que se pode traduzir em uma ação estratégica mais crítica.

\section{d) Reflexão}

A reflexão visou interpretar, discursivamente, os acontecimentos oriundos das ações, propondo modificações aos planejamentos das mesmas, face às evidências observadas, reconstruindo novas ações para o futuro. 


\section{RESULTADOS E DISCUSSÃO}

O uso de metodologias ativas, através da realização das oficinas de maquetes no ensino fundamental e no ensino superior, desperta o interesse dos alunos, contribuindo significativamente no processo ensino e aprendizagem em relação aos conhecimentos geográficos necessários, no que tange a cartografia, em suas formas de ler e interpretar mapas, bem como aos elementos cartográficos presentes nos mapas, como as escalas, legenda, orientação.

Carneiro (2019), a realizar o "Projeto Vida na Metrópole" em uma escola pública da periferia de Fortaleza (CE), no qual utilizou metodologias ativas, com a montagem de maquetes e brinquedos reciclados, tornando as intervenções mais ativas e lúdicas, revela que:

Dar significado para os conteúdos ministrados na escola vem sendo um dos grandes desafios para os professores que, cada vez mais, se deparam com estudantes, em sua maioria, completamente desestimulados e desinteressados. Estas dificuldades são heranças de uma escola que demorou a se adaptar à nova realidade dos estudantes, que possuem novos interesses, outras formas de lidar com a realidade e diversas formas de acesso à informação. Umas das características mais importantes que deve ser estimulada no estudante na escola é a curiosidade, o desejo de entender e saber o porquê das coisas, a escola como um ambiente de educação e conhecimento, deve explorar a curiosidade dos estudantes, utilizá-la a seu favor, e para muitos professores, esse estímulo à curiosidade é um desafio, visto a atual situação das escolas e da educação no país (CARNEIRO, 2019, p. 3152).

A partir das ações práticas, realizadas na escola, foi observado que, no nível de ensino fundamental, o uso de metodologias ativas em sala de aula, a partir da elaboração das maquetes com a representação dos elementos cartográficos, motivou os estudantes a participarem ativamente de todas as fases. A representação se fundamentou na correlação entre os conhecimentos teóricos construídos em sala de aula e pelos conhecimentos desenvolvidos nas vivências de todos e de cada um. Nesse processo, buscou-se colocar o estudante na condição de protagonista de sua própria aprendizagem, estimulando-o a refletir sobre as temáticas trabalhadas.

Conforme o questionário de avaliação, da aplicação da oficina de maquetes, os estudantes da escola gostaram da oficina e se sentiram atraídos e motivados com a realização da atividade.

Acredito que a oficina de maquete auxiliou no ensino da Geografia dos nossos educandos, pois é um recurso didático muito importante, auxiliando na compreensão do conteúdo como no caso das microbacias, além de promover a socialização e a criatividade favorecendo de modo positivo o ensino e a aprendizagem de forma interdisciplinar (PROFESSORA ESCOLA, 2019).

A realização da oficina das maquetes de microbacias apresentou um efeito positivo dentro do ensino aprendizagem, possibilitando a compreensão do conteúdo como no caso das microbacias a associação do local que residem promovendo o pertencimento dos educandos (DIRETORA ESCOLA, 2019). 
Os depoimentos corroboram com Pereira et al. (2015, p. 2), ao afirmarem que, a construção de maquetes geográficas e modelos didáticos em escala reduzida, "possibilitam reconhecer, através da representação, a compreensão do espaço em que o aluno está inserido; pela integração entre professor $\mathrm{x}$ aluno, entre prática x teoria". No mais, as escolas na atualidade enfrentam significativos desafios, desta forma, a elaboração de maquetes, segundo Carvalho (2015, p. 10), torna as "práticas didáticas mais atrativas e interessantes aos olhos dos estudantes".

Ressalta-se que a partir da elaboração das maquetes das microbacias locais, torna-se possível trabalhar com os estudantes diversos conteúdos, entre os quais, a presença dos elementos naturais (florestas, campos nativos, áreas de preservação permanente, rios, etc) e a inserção dos elementos que compõe as paisagens humanizadas (a ampliação das áreas de lavouras, estradas, crescimento urbano, saneamento, resíduos sólidos, poluição, etc), e como a (interdependência) entre estes elementos atingem a microbacia estudada. Além disso, pode ser trabalhado o uso do solo e os impactos disso nas águas (rios, lagos, nascentes, águas subterrâneas (poços), drenagem urbana, etc.). A inserção dessas informações faz com que o modelo tenha aplicabilidade em diversas áreas de recursos hídricos de forma mais dinâmica e interessante, o que contribui e facilita o processo de ensino-aprendizagem (PEREIRA et al., 2015). Com isso, busca-se desenvolver no indivíduo a capacidade de observar, analisar, interpretar e pensar criticamente a realidade e as transformações sofridas pelo mundo, (MANFIO; BALSSAN, 2014, p. 75).

Percebeu-se que, para os estudantes do ensino superior, as atividades com maquetes contribuíram com a formação do futuro professor, desenvolvimento de saberes, habilidades e competências necessárias à prática docente, fortalecendo a construção da identidade do futuro docente. Cabe destacar, que as universidades possuem relevante papel na formação do futuro docente, desta forma, propiciar o contato com diferentes práticas didáticas na formação inicial possibilita a constituição de um professor crítico e reflexivo.

Conforme o questionário de avaliação, cerca de $98 \%$ dos estudantes do nível superior que participaram, salientaram que foi importante a realização da oficina de maquetes, na medida em que se tornou possível materializar, na prática, os conhecimentos teóricos, possibilitando que se apropriem do conhecimento. Assim, pode-se inferir que o principal objetivo de construir maquetes foi atendido, uma vez que as maquetes são reproduções em escalas reduzidas de projetos, regiões ou ambientes naturais, fundamentadas em dados ambientais e/ou variáveis reais do projeto original, e que sua principal função é representar a realidade, por vezes, com destaque para detalhes não vistos em outra forma de representação.

Adorei fazer a oficina, além de aprender muito, eu pude mostrar para minha família nossa região e tivermos o prazer de tirar algumas dúvidas sobre nossa região (ESTUDANTE NÍVEL SUPERIOR A, 2019). 
Esta oficina foi muito didática, com o uso de materiais simples podemos trazer a realidade de uma vasta área territorial para uma mesa de sala de aula (ESTUDANTE NÍVEL SUPERIOR C, 2019).

Ao serem perguntados se pretendiam aplicar a oficina nas aulas da educação básica, 100\% dos estudantes relataram que aplicariam em suas aulas essa oficina, demonstrando que, as maquetes, enquanto recurso didático pedagógico, possibilitam a visualização de elementos geográficos, hidrografia, relevo, urbanização, vegetação entre outros, de forma concreta.

Através da oficina aprendemos como construir uma maquete, uma técnica que no futuro com certeza irei utilizar com os meus alunos. Esta prática detalha o conteúdo que irá ser estudado, mostra como é na realidade facilitando o entendimento dos alunos (ESTUDANTE NÍVEL SUPERIOR D, 2019).

Está oficina foi de grande aprendizado tanto pra mim quanto pra meu filho que estava junto pois a dinâmica da professora proporcionou não só aos adultos entenderem e montar quanto meu filho de 4 anos que usando as sobras dos recortes pode montar a sua maquete usando a sua imaginação quanto ao que estava sendo pedido e deste modo interagindo junto, observei que não seria dificil trabalhar em sala de aula (ESTUDANTE NÍVEL SUPERIOR E, 2019).

Achei ótima a oficina, uma técnica que facilita a compreensão de relevo (ESTUDANTE NÍVEL SUPERIOR F, 2019).

A maquete é uma excelente ferramenta para o (re)conhecimento do território (ESTUDANTE NÍVEL SUPERIOR G, 2019).

Achei ótima a oficina, uma técnica que facilita a compreensão de relevo, de fácil entendimento e aplicaria em sala de aula pois é uma alternativa didática que facilita o ensino/ aprendizagem além de desenvolver outras capacidades no aluno como coordenação motora, atenção (ESTUDANTE NÍVEL SUPERIOR H, 2019).

Esses depoimentos corroboram com Pereira et al. (2015, p. 3), no qual revelam que a ideia principal na construção de um modelo didático para bacias hidrográficas é representar uma visão tridimensional das informações que usualmente são demonstradas em mapas de forma bidimensional. Assim, a realização da oficina de maquetes ofereceu aportes, demonstrando aos estudantes do nível superior (futuros professores) ser necessário e possível atuar de forma diferenciada em sala de aula. Pois a partir da ação prática torna-se possível assimilar conceitos, como curvas de nível, divisores de água, bacias hidrográficas, altitude, escala, entre outros.

Segundo Marcatto (2002), um dos meios é aprender fazendo, o que propicia o repasse de informações pertinentes, úteis e que ajudam a dar sentido às teorias. Sem a prática, ricas ideias podem permanecer para sempre no campo do imaginário, e é comum que acabem se perdendo. Por isso, unir teoria e prática na construção de maquetes para representar as realidades locais é uma das atividades com resultados positivos e que pode ser trabalhada em forma de projetos ou de maneira interdisciplinar. 
A partir das oficinas realizadas os estudantes envolvidos tiveram a possibilidade de aprenderem conteúdos trabalhados nas salas de aula de forma lúdica e prática, fortalecendo o conhecimento teórico adquirido e estabelecendo relações entre conteúdos trabalhados e as práticas realizadas.

$\mathrm{Na}$ escola as atividades foram realizadas com educandos do sexto ano do Ensino Fundamental com o apoio da professora de Geografia. A opção da realização da atividade com está turma se deve ao fato desta estar estudando conteúdos sobre formas de representar o espaço geográfico, entre os quais cita-se as maquetes. Por sua vez, no Ensino Superior, com estudantes do sétimo semestre de um Curso de Licenciatura com área de formação em História, Geografia, Filosofia e Sociologia, os quais se caracterizam enquanto futuros professores, em processo de formação inicial e neste contexto, se faz importante coloca-los em contato com diferentes metodologias e didáticas que auxiliem e qualifiquem sua futura atuação docente.

De acordo com Machado e Di Maio (2008), a maquete é um recurso didático cujo valor está no fato de contribuir para a representação tridimensional do relevo, na medida em que registra e possibilita a visualização das formas topográficas. No entanto, para que a elaboração da maquete se consolide enquanto uma aprendizagem significativa, é necessário que os educandos tenham conhecimentos básicos de cartografia. Esses conhecimentos, de acordo com Simielli et al. (2007), ganham concretude e são mais facilmente incorporados a partir da maquete. De acordo com os autores, a construção da maquete traduz-se, assim, em um processo de educação cartográfica e este raciocínio é válido tanto para as séries iniciais quanto para a aprendizagem na leitura e interpretação de cartas topográficas com estudantes do ensino superior (SIMIELLI et al., 2007, p. 133).

Uma das finalidades da utilização das maquetes no ensino de geografia é auxiliar a formação de raciocínios e concepções de forma que o estudante aprenda a ler e interpretar os acontecimentos vividos, problematizando com os saberes adquiridos. Nesse sentido, reforça-se a necessidade do aprofundamento de práticas e saberes que motivem os estudantes, cujo objetivo, no caso específico da ciência geográfica, é torná-la uma disciplina não apenas de cunho (teórico), distante do mundo vivido dos educandos, mas sim que possibilite contextualizar os fenômenos e o espaço numa dicotomia teoria e prática/vivência diária-(MANFIO; BALSSAN, 2014).

A partir das maquetes pode-se retratar situações do cotidiano, entre as quais os efeitos das ações antrópicas em microbacias em diferentes escalas. Compreender o cotidiano ajuda a "enfrentar o dilema entre conjuntura e estrutura, entre o particular e o geral, aquilo que vejo, ouço, sinto, no meu entorno imediato e o que exige associações que me levam além do aqui e agora, mas que ajudam a entender a situação na qual me encontro" (SERPA, 2020, p. 440).

O conhecimento das inter-relações, que ocorrem entre os fenômenos, permite-desenvolver nos estudantes habilidades geográficas para a compreensão da realidade materializada enquanto resultado de um conjunto de medidas e ações que ocorrem nas mais diferenciadas escalas. Assim, compreender o espaço geográfico na totalidade significa entender como as relações sociais, econômicas, políticas, culturais e ambientais se estabelecem nos diferenciados cenários. 
No caso específico da elaboração da maquete de uma microbacia, como atividade prática apresentada neste trabalho, os estudantes tiveram a possibilidade de compreender o significado de encontrar e reproduzir as curvas de nível, bem como as nascentes do rio principal, seu trajeto, a foz, bem como entender a importância de uma microbacia e o papel de todos e de cada um na preservação da mesma. A correlação destes conhecimentos e as formas de ocupação do espaço permitiu que os mesmos compreendessem quais são os problemas que afetam a microbacia.

Portanto, com base nos resultados do questionário de avaliação, pôde-se identificar que o planejamento e a ação se mostraram eficazes, uma vez que, se conseguiu, através da oferta das oficinas, satisfazer a maioria dos participantes. Nesse sentido, entendemos que "a educação é comunicação, é diálogo, na medida em que não é a transferência de saber, mas um encontro de sujeitos interlocutores que buscam a significação dos significados" (FREIRE 1988, p. 69) e que a Universidade desempenha esse papel importante promovendo o diálogo entre os diferentes níveis de ensino, promovendo também uma interação dialógica com a comunidade.

Assim, professores ao desenvolverem práticas pedagógicas norteadas pelas metodologias ativas, promovendo a autonomia do aluno, exercitam uma atitude crítica e construtiva que fará do participante um profissional melhor preparado (BERBEL, 2011). O uso das metodologias ativas favorece a autonomia do aluno, desperta a curiosidade, estimula tomadas de decisões individuais e coletivas, e desenvolve atividades essenciais para a prática social no contexto do estudante.

Tão importante quanto o desenvolvimento das práticas pedagógicas utilizadas em sala de aula, utilizando metodologias ativas, é a Extensão Universitária, onde os conhecimentos e projetos propostos pelas universidades contemplam as práticas dos professores da educação básica. Fato relevante no que tange ao aperfeiçoamento dos professores que atuam na educação básica, assim como para os acadêmicos das licenciaturas, que serão os futuros protagonistas desse processo.

\section{CONCLUSÃO}

A educação se caracteriza enquanto um conjunto de saberes que envolvem os processos do ensinar e do aprender. Na consolidação do processo ensino-aprendizagem, as metodologias ativas se inserem potencializando o aprendizado, no sentido em que o estudante passa a ser protagonista da ação. Através da atividade de construção da maquete de uma microbacia foi possível trabalhar diversos conceitos tendo como temáticas maiores o uso do solo e os impactos nos recursos hídricos.

Tendo em vista que os recursos hídricos são essenciais e necessários para a sobrevivência humana, bem como para o desenvolvimento de uma série de atividades econômicas e, que estes encontram-se atualmente desprovidos de proteção, ameaçados pelas fontes de poluição, reflexos das ações antrópicas, considera-se necessário trabalhar de forma prática tais questões com os estudantes, possibilitando condições para que a leitura e interpretação do espaço vivido ocorra a partir 
da identificação dos problemas presentes. Assim, consideramos a elaboração da maquete como um importante instrumento no auxílio da construção do conhecimento acerca de bacias hidrográficas, recursos hídricos e uso do solo por permitir a materialização do espaço em escala reduzida.

Além disso, as maquetes podem ser construídas com estudantes de diferenciadas idades e fases, desde alunos do ensino fundamental, médio e superior, bem como comunidade em geral, comitês de bacias, poder público e comunidades locais para conhecimento e tomada de decisão na gestão dos recursos hídricos local ou regional, conforme a necessidade e foco.

O baixo custo dos materiais utilizados e a fácil construção auxiliou no processo de ensino-aprendizagem. As curvas de nível proporcionam um entendimento real do que ocorre, muito além do visualizado de forma abstrata no livro didático.

De forma geral, a proposta foi bem aceita pelos estudantes, os mesmos demonstraram interesse e as atividades foram realizadas comprometida. Esse estímulo dos alunos proporcionou um ganho cognitivo relevante sobre a temática abordada, isto significa dizer que ocorreu ganho de conhecimento quando utilizado essa metodologia diferenciada para trabalhar conteúdos e conceitos relacionados a temática água.

Portanto, inferimos que a atividade de confecção de maquete em sala de aula proporcionou a inter-relação entre teoria e prática, permitindo ao estudante incentivos para a arguição de um questionamento interdisciplinar da realidade, transportando-o ao alcance de uma análise crítica do presente, dentro do contexto abordado.

\section{REFERÊNCIAS}

BASTOS, C. C. Metodologias Ativas. Educação \& Medicina. 2006. Disponível em: https://bit.ly/ 3jie9rQ. Acesso em: março/2021.

BERBEL, N. As metodologias ativas e a promoção da autonomia dos estudantes. Semina -Ciências Sociais e Humanas, Londrina, v. 32, n. 1, p. 25-40, jan. /jun. 2011.

CARNEIRO, M. B. Metodologias ativas nos anos finais do ensino fundamental: intervenções do PIBID com o projeto vida na metrópole. ENCONTRO NACIONAL DE PRÁTICA DE ENSINO DE GEOGRAFIA POLÍTICAS, LINGUAGENS E TRAJETÓRIAS, 14, 2019. Anais... Universidade Estadual de Campinas, 29 de junho a 4 de julho de 2019. p. 3153- 3162. Disponível em: https://bit.ly/ $3 \mathrm{vrEp} 80$. Acesso março/2021.

CARR, W.; KEMMIS, S. Teoría crítica de la enseñanza. Barcelona: Martínez Roca, 1988. 
CARVALHO, J. W. L. T. Bacias Hidrográficas Simuladas em Maquetes. Prática Pedagógica Para o $6^{\circ}$ Ano do Ensino Fundamental. Trabalho de Graduação (Licenciatura em Geografia) - Setor de Ciências da Terra, Universidade Federal do Paraná, Curitiba, 2015.

CASTELLAR, S. V. A cartografia e a construção do conhecimento em contexto escolar. In: ALMEIDA, R. D. (org.) Novos rumos da cartografia escolar: currículo, linguagem e tecnologia. São Paulo: Contexto, 2011.

COSME, J.S. et al. O uso da maquete e as metodologias ativas no ensino de geografia da Paraíba: Ações educativas no IFPB de Campina Grande- PB. In: CONGRESSO NACIONAL DE EDUCAÇÃO CONEDU, 6, 2019. Anais...

ELLIOT, J. El cambio educativo desde la investigación-acción. Madrid: Morata, 1993.

FREIRE, P. Educação como prática da liberdade. 23. ed. Rio de Janeiro: Paz e Terra, 1999.

FREIRE, Paulo. Pedagogia do Oprimido. 18. ed. Rio de Janeiro: Paz e Terra, 1988.

LUZ, R. M. D.; BRISK, S. J. Aplicação didática para o ensino de Geografia Física através da construção e utilização de maquetes interativas. Anais.. In: ENCONTRO NACIONAL DE PRÁTICA DE ENSINO EM GEOGRAFIA, 10, 2009. Anais... Porto Alegre, agosto/setembro, 2009. Disponível em: https://bit.ly/3AWtyEh. Acesso março/2021.

MACHADO, L. R.; DI MAIO, A.C. A maquete de relevo e o estudo de microbacias no ensino da Geografia. In: IX Encontro Latino Americano de Iniciação Científica e V Encontro Latino Americano de Pós-Graduação - Universidade do Vale do Paraíba, 2 de mai de 2008. Disponível em: https://bit.ly/ 3aPqM9j. Acesso 10-09-2020.

MANFIO, V. ; BALSSAN, J. B. Geografia escolar: práticas pedagógicas e o ensino-aprendizagem do conteúdo de regiões brasileiras. Geographia Opportuno Tempore. UEL - Londrina, v. 1, n. 2 , número especial, p. 68-84, jul./dez. 2014. ISSN: 2358-1972.

MARCATTO, C. Educação ambiental: conceitos e princípios. Belo Horizonte: FEAM, 2002.64 p.

OLIVEIRA, B. R.; MALANSKI, L. M. O uso da maquete no ensino de geografia. Extensão em Foco, Curitiba, n. 2, p. 181-189, 2008. 
PEREIRA, K. B. et al. Construção de modelo de uma bacia hidrográfica como ferramenta didática na área de recursos hídricos. In: SIMPÓSIO BRASILEIRO DE RECURSOS HÍDRICOS, 212015. Anais... Disponível em: https://bit.ly/3DXVrxs. Acesso em: 10 set. 2020.

SERPA, A. Uma geografia que se pratica no dia a dia. Revista Geosaberes, Fortaleza, v. 11, p. 437-449, 2020.

SIMIELLI, M. E. R. et al. Maquete de relevo: um recurso didático tridimensional. Boletim Paulista de Geografia. São Paulo, Número 87, p. 131-148, dez. 2007.

SIMIELLI, M. H.; GIRARDI; G.; BROMBERG, P. ; MORONE, R.; RAIMUNDO, S.L. Do Plano Tridimensional: a Maquete como Recurso Didático. Boletim Paulista de Geografia, n. 70. São Paulo: AGB, AGB, 1992. Disponível https://bit.ly/3vtw8AD. Acesso 10 set. 2020. 